\title{
The russian agricultural sector in the innovative component of the country's food security
}

\author{
L.A. Molchanova ${ }^{1, *}$, O.S. Akupiyan ${ }^{2}$, D.P. Kravchenko ${ }^{2}$, Z.Ch. Pak $^{2}$, and N.I. Chovgan ${ }^{2}$ \\ ${ }^{1}$ Russian Academy of Entrepreneurship, Moscow \\ ${ }^{2}$ Belgorod State Agrarian University named after V.Ya. Gorin
}

\begin{abstract}
Achieving competitiveness in the global world economy system requires strengthening the innovative direction of representatives of the domestic agro-industrial sector. The innovative component of the agricultural sector also plays an important role in solving the country's food security. The article considers the basics of the development of innovative activity of agro-industrial enterprises and the impact of innovative activity in the agro-industrial complex on the country food security. Obstacles are analyzed and priority directions of innovative development of agro-industrial enterprises are reflected.
\end{abstract}

\section{Introduction}

In the conditions of the active information society development and the knowledge economy formation, the innovative sphere of activity, which is associated with the sustainable economic growth of any state, is of particular importance. As international experience shows, national security increasingly depends not on the natural resource potential of the state, but on progressive trends in the transformation of its innovative sphere, which, covering various types of economic activity, predetermines their constant modernization and transition to new development models. In this context, the problems of studying the correlations between innovative and economic development of the state and assessing the impact of innovative factors on various components of its economic security become particularly relevant.

The food security of states in modern conditions can be considered as one of the most significant components of national security since it is directly related to ensuring public health and reproduction of the population. Provision of one of the basic human needs - the need for nutrition at the present stage of society's development becomes impossible without the use of scientific and technological progress, in particular, in agriculture and food industry. Accordingly, the degree of food security of the population, especially in the conditions of the formation of a post-industrial society, directly depends on the volume of innovation implementation in the practice of agro-industrial enterprises and in the sphere of state regulation of relevant economic activities.

It should be noted that "... the innovative way of agricultural development for most developed economies of the world is a kind of guideline, and the search for models of

\footnotetext{
${ }^{*}$ Corresponding author: milan7777@rambler.ru
} 
innovative development and the definition of favorable conditions for innovation activity formed the basis of theory and practice. For Russia, this problem is especially relevant, since the country is significantly inferior in terms of innovative development to countries that have recently realized the need to transition to an innovation-type economy. One of the main obstacles to the innovative development of the agro-industrial complex are serious problems in the institutional environment" [2].

According to the modern scientific paradigm, the innovative nature of the agriculture development, which affects food security, provides for the implementation of modernization processes in the agro-industrial complex, as well as the formation of the legal framework for the activities of enterprises. The intensification of integration processes and the significant strengthening of information and communication technologies creates special conditions in which the principles of enterprise activity, patterns of agricultural development and mechanisms of influence on the industry change.

The relevance of determining the role of innovation in the economic system occupies one of the leading places. Innovation is the main factor of long-term economic development. The widespread introduction of innovations in all areas of the enterprises' activities ensures their successful functioning and provides competitive advantages. An informative analysis of scientific research shows that the foundations of the theory were developed on the issues of innovation, at the origins of which Y. Schumpeter [16] was in the early XX century. Many foreign scientists, including P. Drucker [7], J. Galbraith [5], J. Bell [3], M. Castels [11] considered the "innovative" economy as the basic concept of a post-industrial society.

Leading Russian scientists and specialists conducted research devoted to the prospects of the agro-industrial complex development, the feasibility of innovation, the problems of innovation in Russia, the impact of the regulatory framework on innovation activity. In particular, these issues are reflected in the works of Russian scientists, including I.G. Ushachev, I.S. Sandu, A.I. Altukhov, who proposed to introduce new methods of updating the material and technical base into the domestic sector of the agro-industrial complex.

The fundamental research of Russian scientists S.Yu. Glazyev, N.A. Voronov, V.V. Golbert, J.M. Kozlova, E.O. Naumenko, et al. is devoted to the study and generalization of various trends in the development of innovations, including in the agricultural sector.

Despite the fact that valuable experience has been summarized in the economic literature in the direction of determining the value of innovation activity, a priority approach to its active application in the domestic agro-industrial complex and its impact on the country's food security has not been found to date, which predetermined the relevance of this study.

\section{Materials and Methods}

The purpose of the article is to study the features of innovative development in agriculture to stabilize the efficiency and growth of the agricultural sector in Russia, which is fundamental in solving the issues of country's food security.

The research methodology is based on existing scientific concepts, basic provisions and views on the goals and mechanisms of innovative development of the agricultural sector.

To solve the tasks set, the authors used general scientific and special research methods: historical and economic - to analyze the genesis of theories and practices of innovative processes in the conditions of transformation of the agricultural sector of the country; abstract-logical method - to substantiate and concretize the main provisions of the innovative development of agriculture; statistical and economic - to study the dynamics of economic parameters of the development of individual components of the domestic agroindustrial complex, tabular and graphical representation of the results obtained. 


\section{Research}

Studying the features of innovative development of enterprises of the agro-industrial sector, V.A. Solomatin defines the essence of innovation activity in the agro-industrial complex as "... a special process of organizing management on the basis of an extensive network of rationally connected small and large innovative enterprises capable to carry out technological changes in agro-industrial production quickly and at minimal cost through the development, production and sale of innovative products and innovative services, to provide competitive high-tech products" [14].

He refers the following to innovative enterprises "... innovation centers, technoparks, research formations, technopolises, innovative business incubators, which should be engaged in the development, production and sale of innovative products and the provision of innovative services, the volume of which exceeds $70.0 \%$ of their total volume of products and services in monetary terms" [14].

The current state of innovation activity in Russia, and especially in the agricultural sector of the economy, is defined by most economic researchers as unsatisfactory or crisis one [1].

It should be noted that "... the innovative potential of the agro-industrial complex in our country is used only by $4-5 \%$, while in the USA this figure is $50 \%$. The share of high-tech products in the agro-industrial complex of Russia does not exceed $0.3 \%$ of the total volume, and in developed countries it is more than 20\%" [13]. The main indicator "... measuring innovation activity is the amount of costs that the state spends on innovation" [13]. Figures 1-2 show the dynamics of the structure of internal research and development costs by type of economic activity in Russia in recent years.

For comparison, the share of expenditures on research and development in the GDP of foreign countries has been constantly growing in recent years: the GDP intensity in the EU28 countries increased from $1.5 \%$ in 2010 to $2.03 \%$ in 2020 (Fig. 1, 2). In addition, to stimulate the EU's competitiveness in the world, one of the five objectives of the Europe 2020 strategy is to increase the knowledge intensity of GDP to $3.0 \%$ by 2020 [17]. A comparison of the knowledge intensity of Russia's GDP with the EU-28 countries as a whole, and with the most developed countries of the European Union in 2020 shows that this indicator in Russia is 0.4 points less than the average in the EU-28 countries and 2 times in the leading countries in terms of innovative development - Finland, Sweden (Fig. 1). [4]

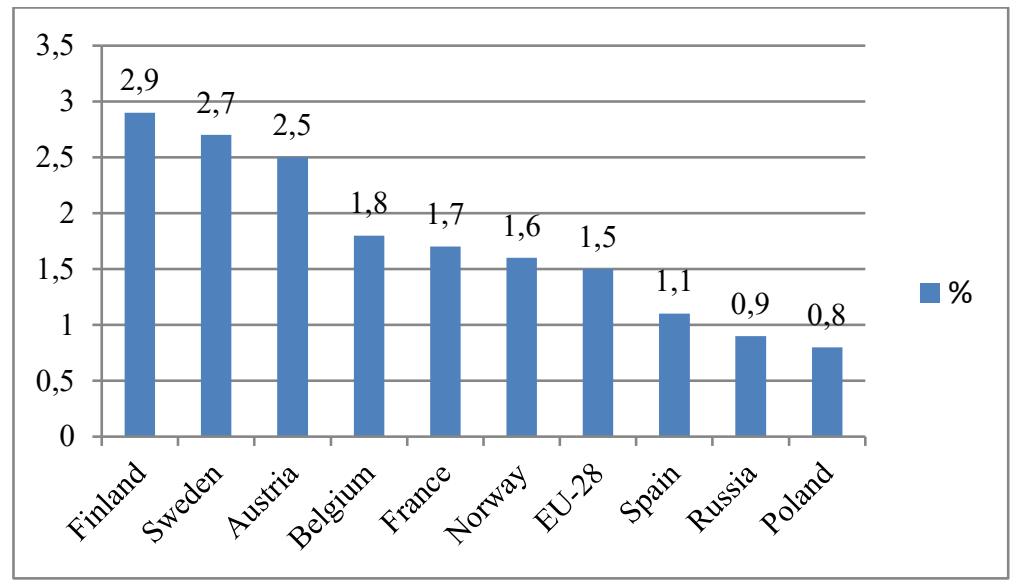

Fig. 1. Indicators of the GDP intensity of Russia and some EU countries in 2010, \%* Compiled by the authors. 


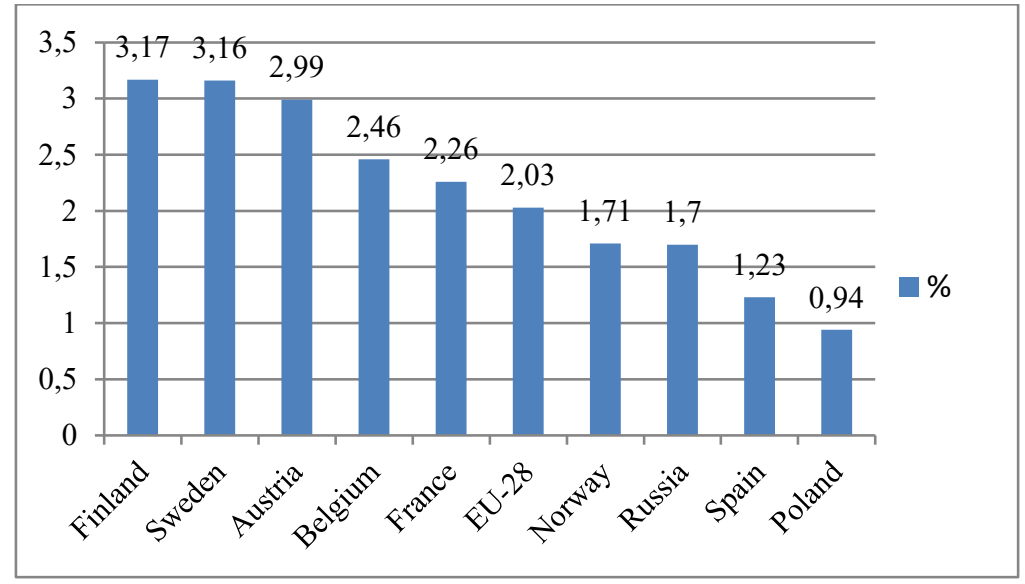

Fig. 2. Indicators of the GDP intensity of Russia and some EU countries in 2020 , \%* Compiled by the authors.

The main indicator measuring innovation activity is the amount of costs that the state spends on innovation. Figure 3 shows the dynamics of the structure of internal costs for research and development in the field of agricultural sciences in Russia in 2020.

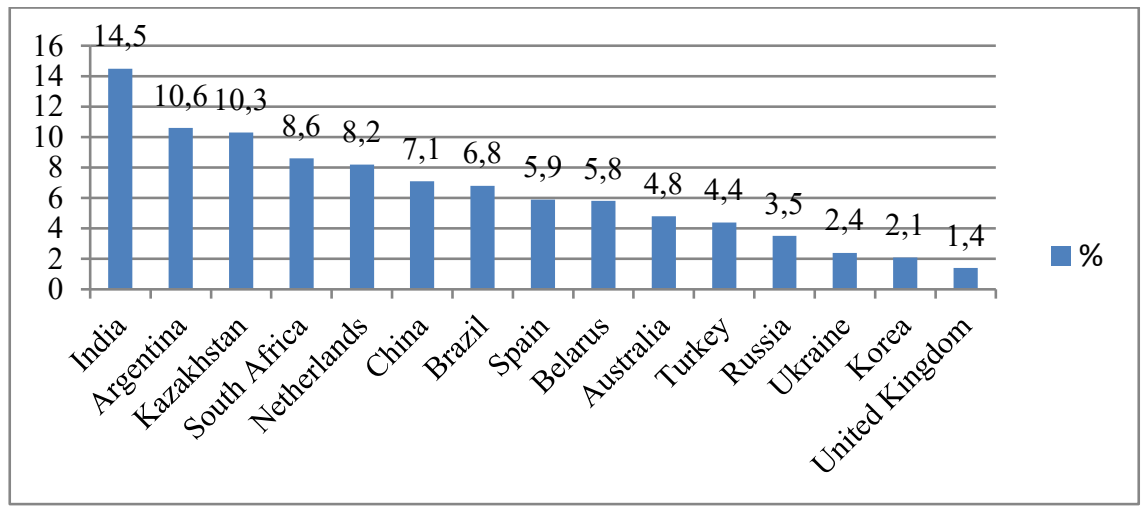

Fig. 3. Share of domestic research and development expenditures in the field of agricultural sciences in various countries (2020), \%*

*Compiled by the authors

A comparison of similar indicators in Russia and BRICS countries according to data for 2020 shows that agricultural science field accounts for $3.5 \%$ of domestic research and development costs, while in India this figure reaches $14.5 \%$, Argentina - 10.6\%, South Africa $-8.6 \%$, China - 7.1\%, Brazil - $6.8 \%$.

The current state of scientific sphere development in the agro-industrial complex, despite the annual growth in budget items of various levels, should not condemn Russia to the role of a backward state in the global environment. Analyzing this provision, it is advisable to recall the words of Academician of the Russian Academy of Sciences I.G. Ushachev, who in 2019 noted that the majority of domestic enterprises in the agricultural sector today are at least half a century behind the enterprises of the same sector in developed countries in terms of technical level [17]. Regarding the negative dynamics of the indicator of the research intensity of Russia's GDP, which has been slowly gaining momentum over the past ten years, it is appropriate to pay attention to the opinion of 
experts who are convinced that with the research intensity of GDP less than $1.0 \%$ per year for 5-7 years, the destruction of the scientific and technical potential of the country begins.

It should also be noted that the share of government spending on science in the cost of agricultural products amounted to $0.7 \%$ of the cost of output in 2020 . The volume of expenditures on agricultural science from the State budget per 1 hectare of agricultural land (11.2 rubles) in Russia was an order of magnitude less than similar indicators in developed countries (for example, France 11 euros, Germany 13 euros).

The number of protection documents received for inventions for agriculture and plant varieties in 2020 amounted to 234 patents, in 2017 - 237 patents. The number of agroformations in which innovations were introduced amounted to 4,076 or $3.9 \%$ of the total number of agricultural enterprises and farms in 2020.

The current situation is a consequence of the improper transfer of the Russian economy to the innovative path of development, the formation of a domestic innovation system that would ensure its implementation, the improper use of planning methods at all levels of management (system analysis, forecasting, optimization, program-targeted management methods), the low level of innovative culture of employees of public authorities.

The way out of this situation can be investments, the volume of which depends on the financial condition of enterprises and the financial resources available to them.

In this case, the situation with the pandemic that arose as a result of a new coronavirus infection in 2020 showed that most sectors of the Russian economy turned out to be unprofitable, and only in the agricultural sector the highest rates were obtained with an increase of up to $86 \%$.

Consequently, the enterprises have demonstrated the presence of investment attractiveness in the agricultural sector, on the full development of which the food security of the country depends.

Moreover, the development of innovative technologies in the agro-industrial complex has an equally significant role and impact on the country's food security.

\section{Discussion}

Over the past five years, many conclusions have been made on the discussion platforms of various forums and round tables regarding the development of a competitive Russian agroindustrial complex. Scientists and practitioners in the light of recent events (food embargo and import substitution processes) have done a lot of work, identified key problems and measures to overcome the current situation. The final event can be recognized as the XXI April International Scientific Conference on the Problems of Economic and Social Development prepared by the Institute of Agricultural Research of the Higher School of Economics together with the National Association for Technology Transfer and the Skolkovo Foundation in April 2020 and the Report "Innovative development of the agroindustrial complex in Russia. AGRICULTURE 4.0" [8]. The document includes all the key areas of domestic agro-industrial complex development for the future, where innovative criteria with their investment component are identified as a priority, since only advanced technologies and their proper financing can fully bring the Russian agro-industrial sector to world markets.

In the future, Russian farmers need to avoid the supply of raw materials abroad for the supply of finished/ processed products, while increasing their investment attractiveness. In fact, agribusiness owners, private investors and bankers have a reason for profitable placement of funds in this sector in the hope of receiving good dividends in the future and their quick payback. Nevertheless, in this case, the state needs to carry out not less significant work to support not only financial in the form of subsidies, grants and guarantees, but also to organize a flexible regulatory system capable of adapting to new 
conditions in a timely manner. The problem of ensuring the consistency of Russian and international standards, the development of international cooperation in the field of certification and licensing also requires special attention.

To improve the innovative component of the agricultural sector, the summary of the forum proposes to create a specialized Fund for the development of innovations in agriculture, which, within the framework of the main mandate, will be able to support any innovative projects relevant to agri-food issues.

In addition, soon, increased attention should be paid to the reorganization of agricultural science and education, based on the fact that the problem of implementing the innovative path of the Russian agro-industrial complex development is the reduction of human resources. The indicated trend is characteristic both for the scientific sector, where it is expressed in a decrease in the number of researchers and the aging of personnel, and for the agro-industrial complex, where it is associated with a growing shortage of qualified personnel.

\section{Conclusion}

The allocation of investment resources should be proportional to the contributions of industries to the country's economy. For the successful implementation of innovative activities in agriculture, investments should be increased significantly. It is only under such conditions that technical and technological transformations of agricultural production and the development of research-intensive resource-saving technologies are possible, which make it possible to increase the competitiveness of agricultural products and production efficiency, to ensure economic growth.

Thus, the innovative development of enterprises in the agricultural sector directly depends on the development of innovative agricultural infrastructure. It is the totality of enterprises that use the achievements of science and technology, economic and informational conditions for the development of innovations that contribute to the renewal of the product range, the creation of jobs, and the multiplication of the scientific and technical potential of the agricultural sector of Russia. In addition, the innovative development of enterprises in the domestic agricultural sector will reduce social tension in rural areas, increase the well-being of the rural population, and give impetus to the development of rural areas and their infrastructure.

\section{References}

1. A. I. Altukhov, The paradigm of food security in Russia. monograph 685 (M.: Youth Development and Support Fund "Personnel Reserve", 2019)

2. V. A. Barinova, V. A. Eremkin, and S. P. Zemtsov, Electronic bulletin 49, 27-51 (2015)

3. J. Bell and G. Kann, The new technocratic wave in the West, 453 (M.: Progress, 1986)

4. Global Innovation Index 2020 Who will finance innovations: The main conclusions.Electronic source of the World Intellectual Property Organization/ access mode: https://www.wipo.int

5. J. Galbraith, New Industrial Society, 602 (Moscow: AST, 2004)

6. Deming U. Edward, New Economy, 208 (Moscow: Eksmo, 2006)

7. P. Drucker, The Era of the gap: guidelines for our changing society, 280 (M.: "I.D. Williams" N, 2007) 
8. N. V. Orlova, E. V. Serova, D. V. Nikolaev, et al., Innovative development of the agroindustrial complex in Russia. Agriculture 4.0 [Text]: rep. to XXI Apr. International Scientific Conference on Problems of Economic and Social Development, Moscow, edited by N V Orlova; Nat. Research Uni-ty "Higher School of Economics" 128 (M.: House of Higher School of Economics, 2020)

9. R. Jensen, The Dream Society, 360 (St. Petersburg: Publishing House of the Stockholm School of Economics in St. Petersburg, 2004)

10. Crawford, Electronic digital society, 120 (M.: Relf-buk, 1999)

11. M. Castels, The Information Age: Economy, Society and Culture, 540 (Moscow: Higher School of Economics, 2000)

12. T. Sakaya, The value created by knowledge, or the History of the future. The New Postindustrial Wave in the West: Anthology, 240 (M.: Academia, 1999)

13. Certificate on the state of scientific research conducted in the interests of agriculture and the agro-industrial complex of Russia - Electronic source of the Ministry of Agriculture of the Russian Federation/ access mode: https://mcx.gov.ru/

14. V. A. Solomatin, Theory and practice of social development 8, 295-299 (2011)

15. J. Stigler, Economic theory of information Theory of the firm. Milestones of economic thought. V. 2 (St. Petersburg: Economic School, 1995)

16. J. Schumpeter, Theory of economic development, 203 (M.: Progress, 1982)

17. I. G. Ushachev, A. V. Kolesnikov, and V. S. Chekalin, Agroindustrial complex: economics, management 5, 22-31 (2019) 